\title{
'Thermometer' Ions can Fragment Through an Unexpected \\ Intramolecular Elimination: These are Not the Fragments You are \\ Looking For
}

Supporting Information

Christian leritano, ${ }^{a, b, c}$ W. Scott Hopkins ${ }^{a, b, c, d *}$

a Department of Chemistry, University of Waterloo, 200 University Avenue West, Waterloo, Ontario, N2L 3G1, Canada. E-mail: shopkins@uwaterloo.ca

${ }^{\mathrm{b}}$ Waterloo Institute for Nanotechnology, University of Waterloo, 200 University Avenue West, Waterloo, Ontario, N2L 3G1, Canada.

c Watermine Innovation, Waterloo, Ontario, NOB 2T0, Canada.

${ }^{d}$ Centre for Eye and Vision Research, Hong Kong Science Park, New Territories, 999077, Hong Kong.

Keywords: mass spectrometry, collision induced dissociation, syn periplanar elimination, fourmembered transition state 


\section{Table of Contents}

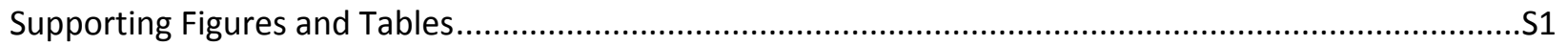

Supplementary Section S1 - Synthesis of the benzylpyridinium derivatives ...........................................11

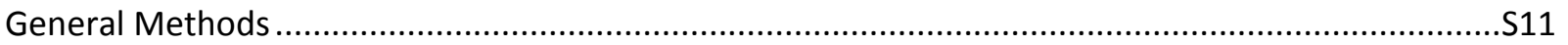

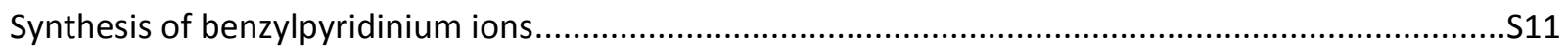

General procedure for the synthesis of O-alkylated 4-hydroxybenzaldehydes (2a-2d) .................S11

General procedure for the synthesis of O-alkylated benzylchlorides (3a-3d) ................................S12

General procedure for the synthesis of O-alkylated benzylpyridinium chlorides (4a-4d) ..............S13 


\section{Supporting Figures and Tables}

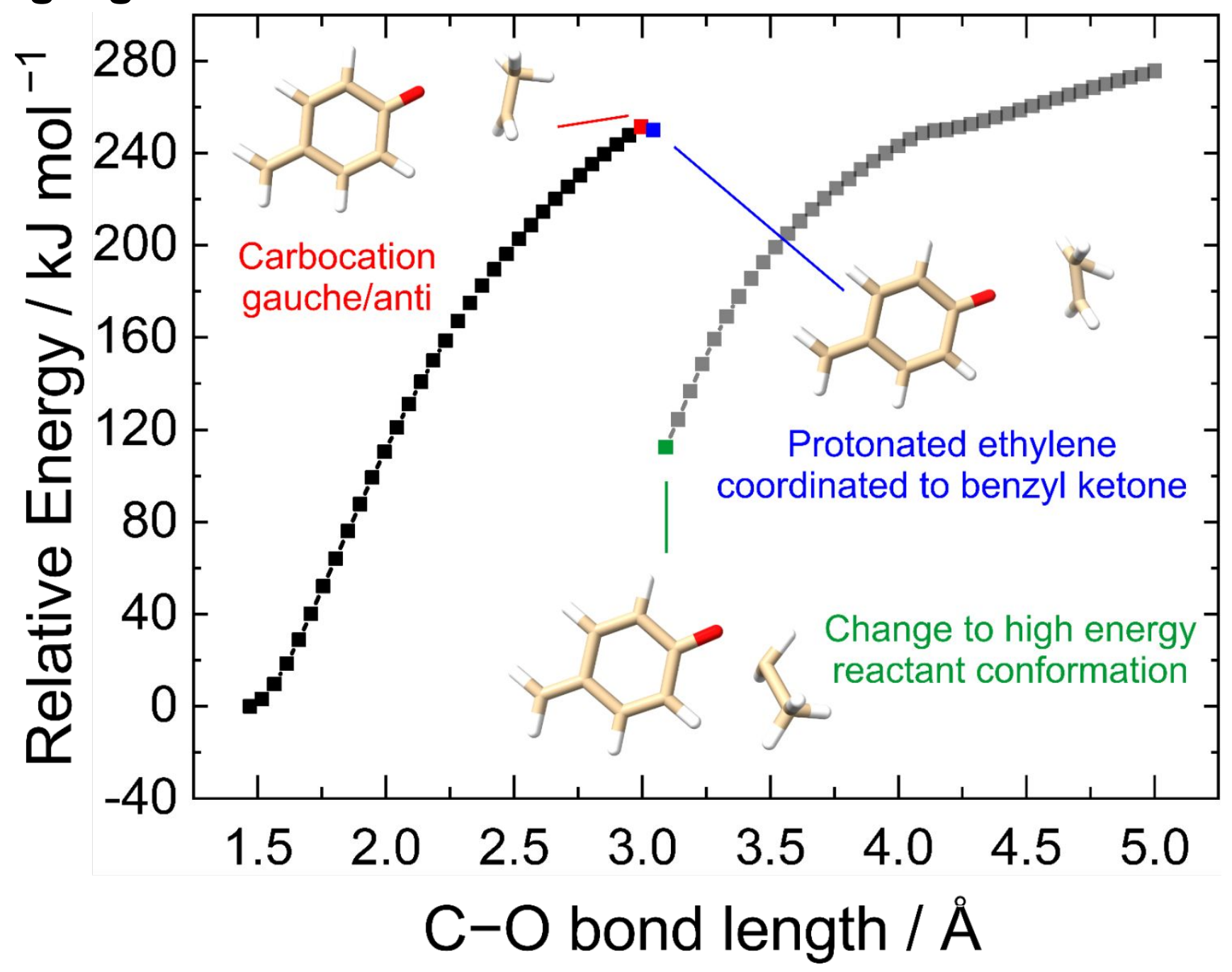

Figure S1. Relaxed potential energy surface scan of 4-ethoxybenzylium (5a). Elongation of the C-O coordinate leads to a carbocation coordinated to the oxygen centre of the benzylium moiety (red), which transitions to a protonated ethylene (blue). Further elongation from this point reforms the reactant ion in a high energy configuration with "swapped" atom labels in the ethyl chain. 


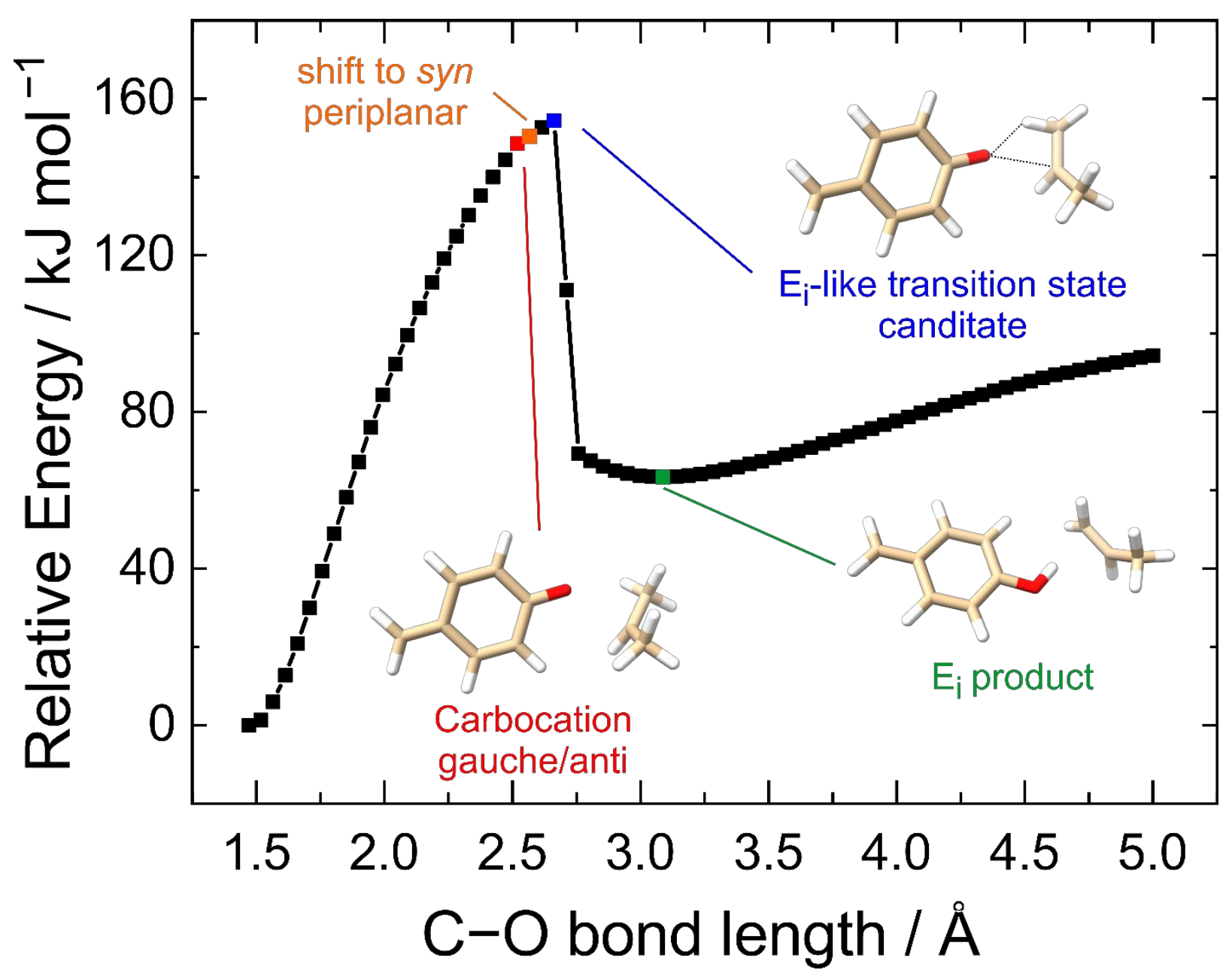

Figure S2. Relaxed potential energy surface scan of 4-isopropoxybenzylium (5b). Elongation of the C-O coordinate leads to a carbocation coordinated to the oxygen centre of the benzylium moiety (red), exhibiting a gauche/anti configuration for the transferable protons with respect to the oxygen centre. Further elongation from this point enables a syn periplanar conformation, generating a reactive conformation capable of proton transfer. A candidate structure for the $\mathrm{E}_{\mathrm{i}}$-like transition state is eventually reached; further elongation from this point optimizes the structure to the $E_{i}$ product, which eventually reaches the minimum energy conformation upon further elongation of the $\mathrm{C}-\mathrm{O}$ coordinate. 


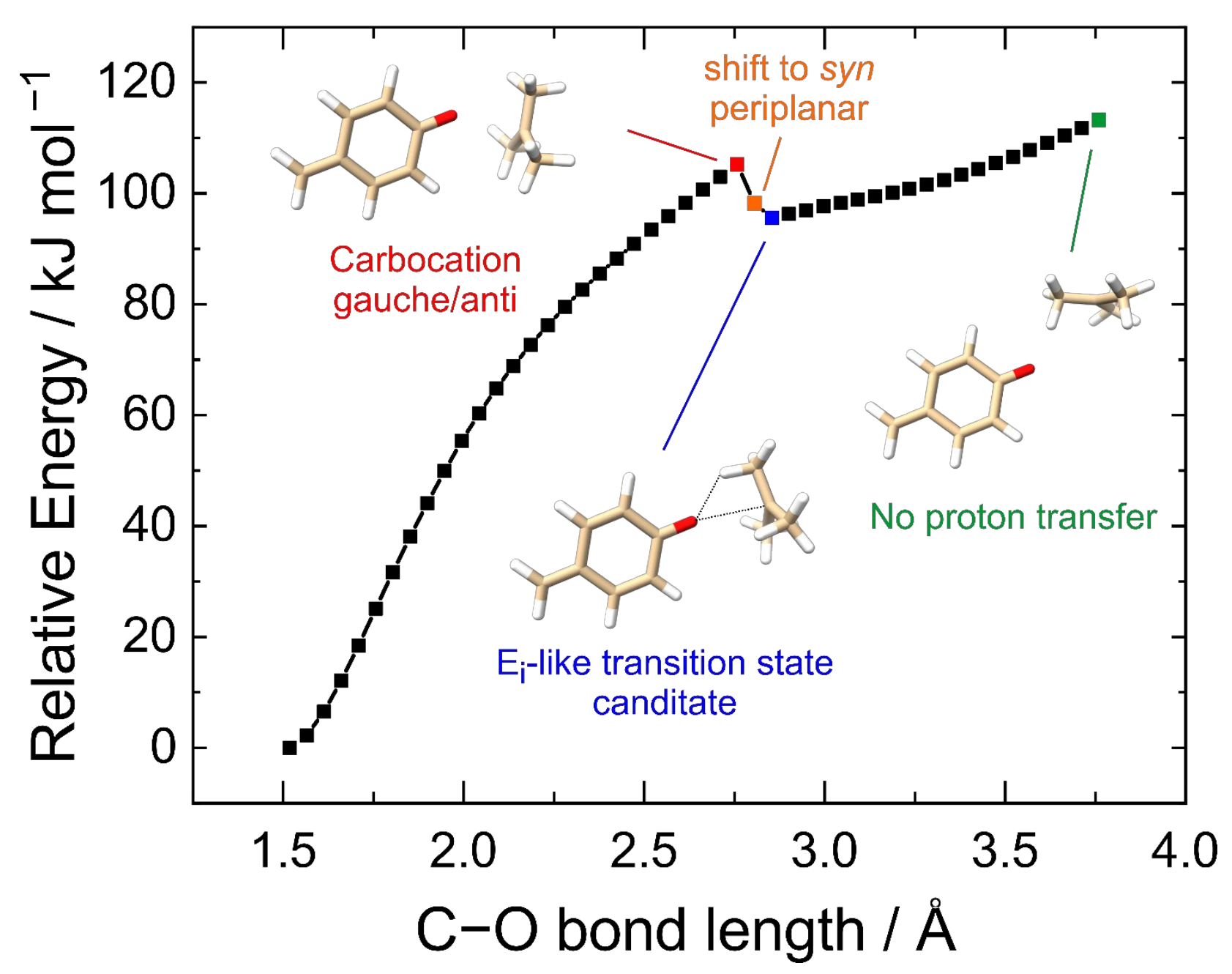

Figure S3. Relaxed potential energy surface scan of 4-tertbutoxybenzylium (5c). Elongation of the $\mathrm{C}-\mathrm{O}$ coordinate leads to a carbocation coordinated to the oxygen centre of the benzylium moiety (red), exhibiting a gauche/anti configuration for the transferable protons with respect to the oxygen centre. Further elongation from this point enables a syn periplanar conformation, generating a reactive conformation capable of proton transfer. In contrast to the PES scan of $\mathbf{5 b}$, no rearrangement to the $\mathrm{E}_{\mathrm{i}}$ product was observed. 


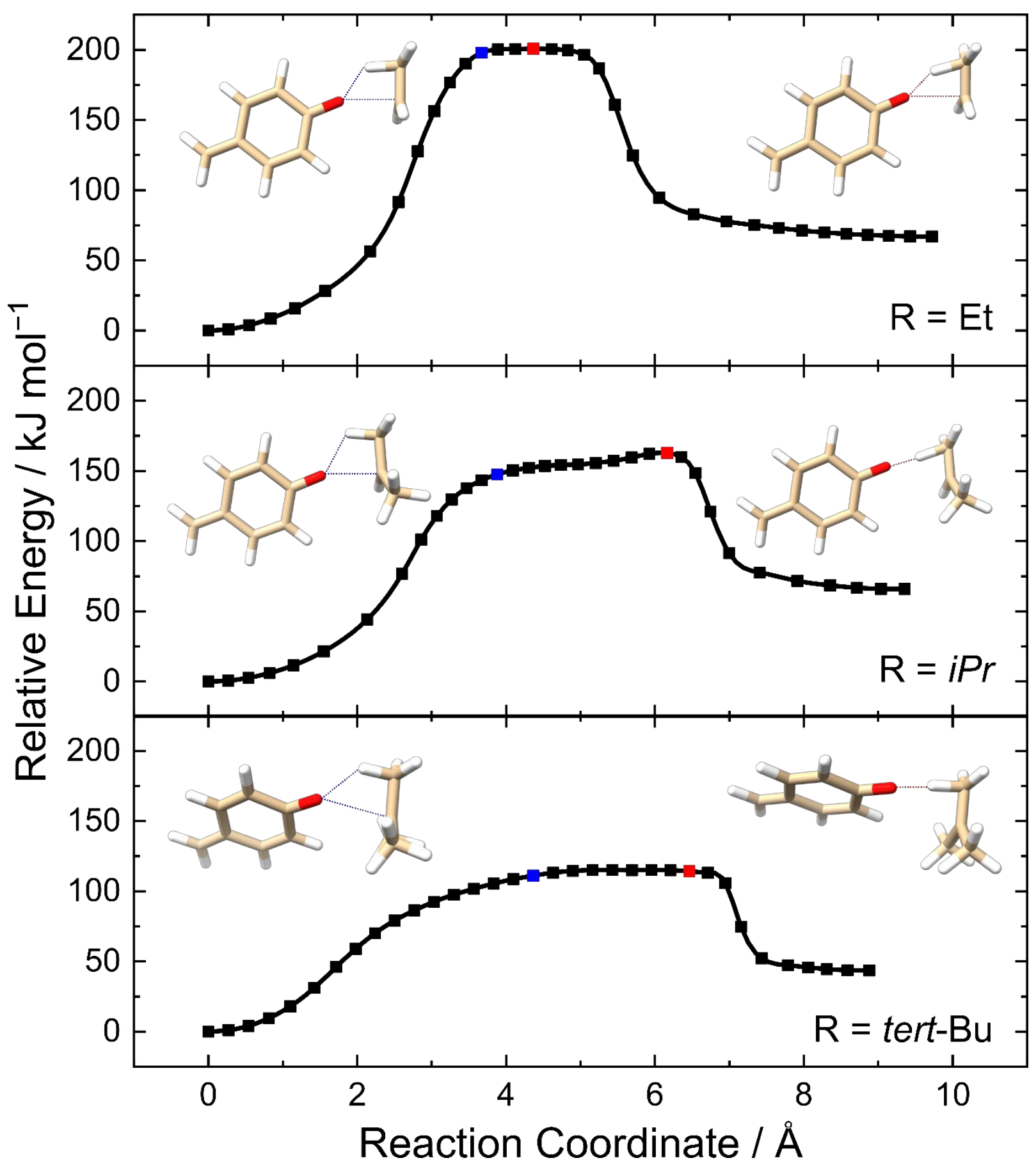

Figure S4. Minimum energy pathway for the intramolecular elimination on 4-ethoxybenzylium (5a, top panel), 4-isopropoxybenzylium (5b, middle panel), and 4-tertbutoxybenzylpyridinium (bottom panel) as determined by the nudged elastic band (NEB) method at the $\omega B$ 97X-D3/def2-TZVPP level of theory using 32 images. Species exhibiting a 4-membered ring motif are shown on the left side of each panel and as a blue dot on the reaction profile. Species corresponding to a saddle point as per the climbing image variant of the NEB method, are shown on the right side of each panel and as a red square on the reaction profile. 


\section{$\mathbf{R}=\mathbf{E t}$}
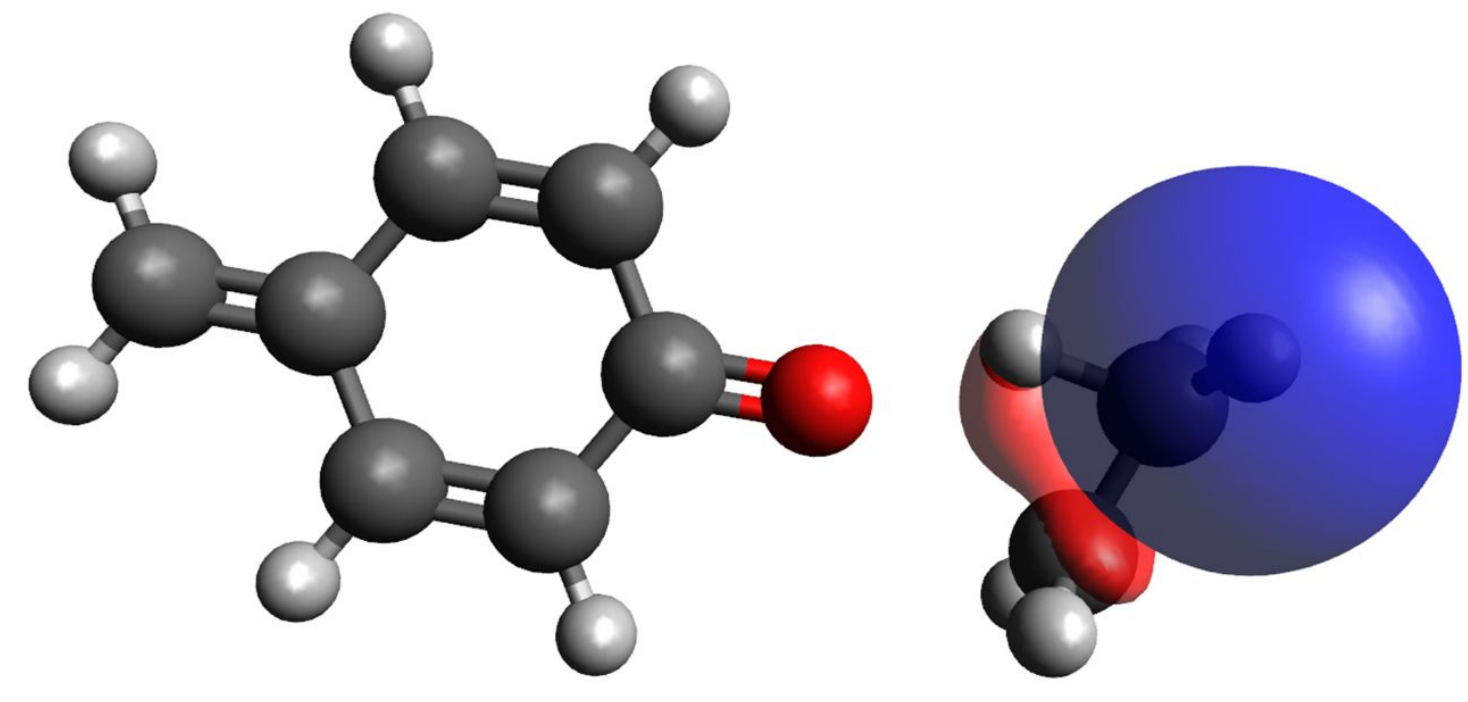

$$
\sigma_{\mathrm{C} 18-\mathrm{H} 19} \rightarrow 2 \mathrm{p}_{\mathrm{C} 15}: 11.7 \mathrm{~kJ} \mathrm{~mol}^{-1} \quad \sigma_{\mathrm{C} 18-\mathrm{H} 21} \rightarrow 2 \mathrm{p}_{\mathrm{C} 15}: 12.3 \mathrm{~kJ} \mathrm{~mol}^{-1}
$$

\section{Total: $24.0 \mathrm{~kJ} \mathrm{~mol}^{-1}$}

Figure S5. Representative natural bonding orbital depicting a hyperconjugation interaction of the transition state leading to the intramolecular elimination product for 4-ethoxybenzylium. Individual and total orbital interactions, as computed by NBO6 at the $\omega$ B97X-D/def2-TZVPP level of theory, are shown below the representative NBO in $\mathrm{KJ} \mathrm{mol}^{-1}$. 


\section{$\mathbf{R}=\boldsymbol{i}-\mathbf{P r}$}

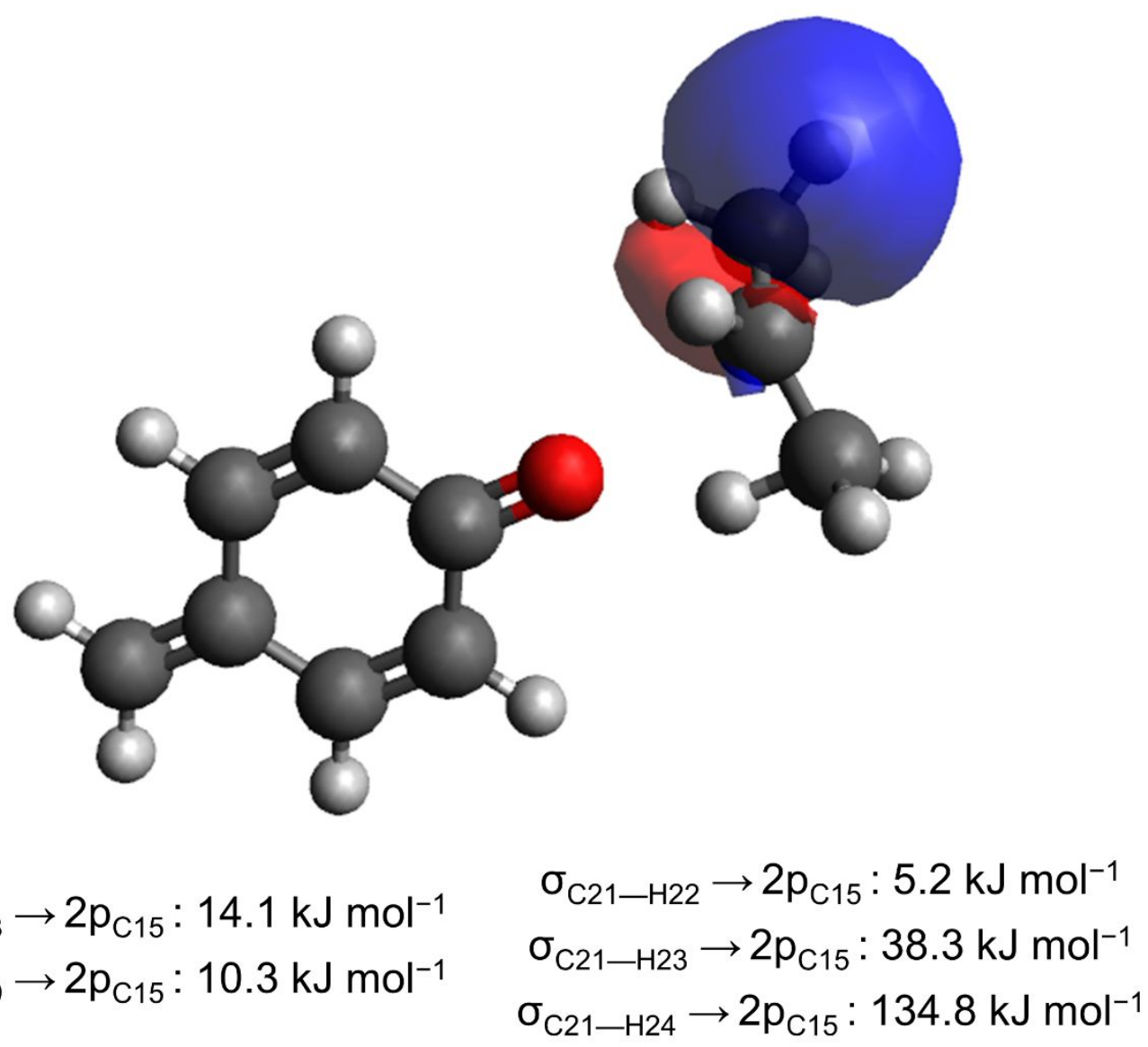

$$
\begin{aligned}
& \sigma_{\mathrm{C} 17-\mathrm{H} 18} \rightarrow 2 \mathrm{p}_{\mathrm{C} 15}: 14.1 \mathrm{~kJ} \mathrm{~mol}^{-1} \\
& \sigma_{\mathrm{C} 17-\mathrm{H} 19} \rightarrow 2 \mathrm{p}_{\mathrm{C} 15}: 10.3 \mathrm{~kJ} \mathrm{~mol}^{-1}
\end{aligned}
$$$$
\sigma_{\mathrm{C} 21-\mathrm{H} 24} \rightarrow 2 \mathrm{p}_{\mathrm{C} 15}: 134.8 \mathrm{~kJ} \mathrm{~mol}^{-1}
$$

\section{Total: $206.0 \mathrm{~kJ} \mathrm{~mol}^{-1}$}

Figure S6. Representative natural bonding orbital depicting a hyperconjugation interaction of the transition state leading to the intramolecular elimination product for 4-isopropoxybenzylium. Individual and total orbital interactions, as computed by NBO6 at the $\omega$ B97X-D/def2-TZVPP level of theory, are shown below the representative NBO in $\mathrm{kJ} \mathrm{mol}^{-1}$. 


\section{$\mathbf{R}=$ tert-Bu}

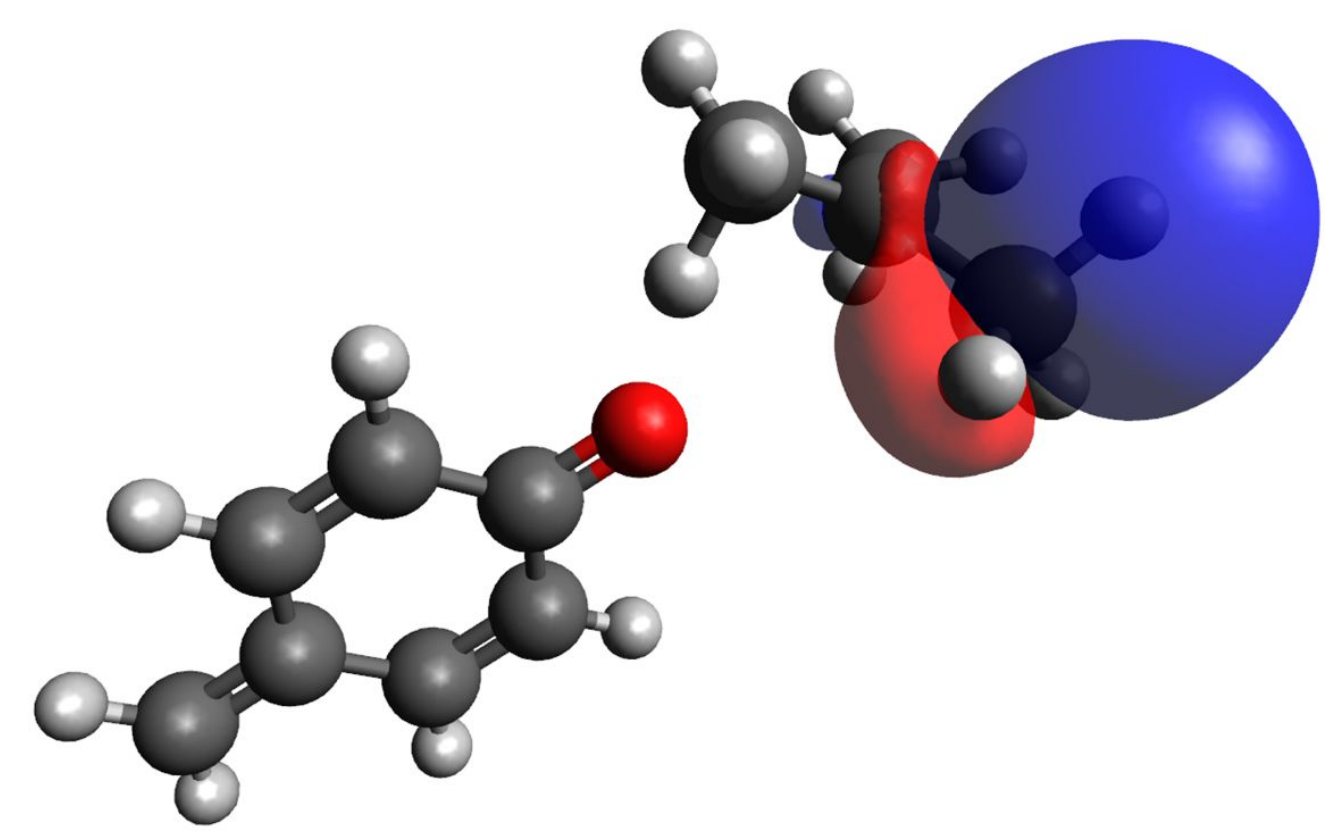

$$
\begin{aligned}
& \sigma_{\mathrm{C} 16-\mathrm{H} 17} \rightarrow 2 \mathrm{p}_{\mathrm{C} 15}: 14.1 \mathrm{~kJ} \mathrm{~mol}^{-1} \\
& \sigma_{\mathrm{C} 16-\mathrm{H} 18} \rightarrow 2 \mathrm{p}_{\mathrm{C} 15}: 10.3 \mathrm{~kJ} \mathrm{~mol}^{-1} \\
& \sigma_{\mathrm{C} 16-\mathrm{H} 19} \rightarrow 2 \mathrm{p}_{\mathrm{C} 15}: 409.3 \mathrm{~kJ} \mathrm{~mol}^{-1} \\
& \sigma_{\mathrm{C} 20-\mathrm{H} 21} \rightarrow 2 \mathrm{p}_{\mathrm{C} 15}: 14.5 \mathrm{~kJ} \mathrm{~mol}^{-1} \\
& \sigma_{\mathrm{C} 20-\mathrm{H} 22} \rightarrow 2 \mathrm{p}_{\mathrm{C} 15}: 20.6 \mathrm{~kJ} \mathrm{~mol}^{-1} \\
& \sigma_{\mathrm{C} 20-\mathrm{H} 23} \rightarrow 2 \mathrm{p}_{\mathrm{C} 15}: 128.0 \mathrm{~kJ} \mathrm{~mol}^{-1}
\end{aligned}
$$$$
\sigma_{\mathrm{C} 24-\mathrm{H} 25} \rightarrow 2 \mathrm{p}_{\mathrm{C} 15}: 4.6 \mathrm{~kJ} \mathrm{~mol}^{-1}
$$$$
\sigma_{\mathrm{C} 24-\mathrm{H} 26} \rightarrow 2 \mathrm{p}_{\mathrm{C} 15}: 50.1 \mathrm{~kJ} \mathrm{~mol}^{-1}
$$$$
\sigma_{\mathrm{C} 24-\mathrm{H} 27} \rightarrow 2 \mathrm{p}_{\mathrm{C} 15}: 108.3 \mathrm{~kJ} \mathrm{~mol}^{-1}
$$

\section{Total: $759.8 \mathrm{~kJ} \mathrm{~mol}^{-1}$}

Figure S7. Representative natural bonding orbital depicting a hyperconjugation interaction of the transition state leading to the intramolecular elimination product for 4-tert-butoxybenzylium. Individual and total orbital interactions, as computed by NBO6 at the $\omega B 97 X-D / d e f 2-T Z V P P ~ l e v e l$ of theory, are shown below the representative NBO in $\mathrm{kJ} \mathrm{mol}^{-1}$. 


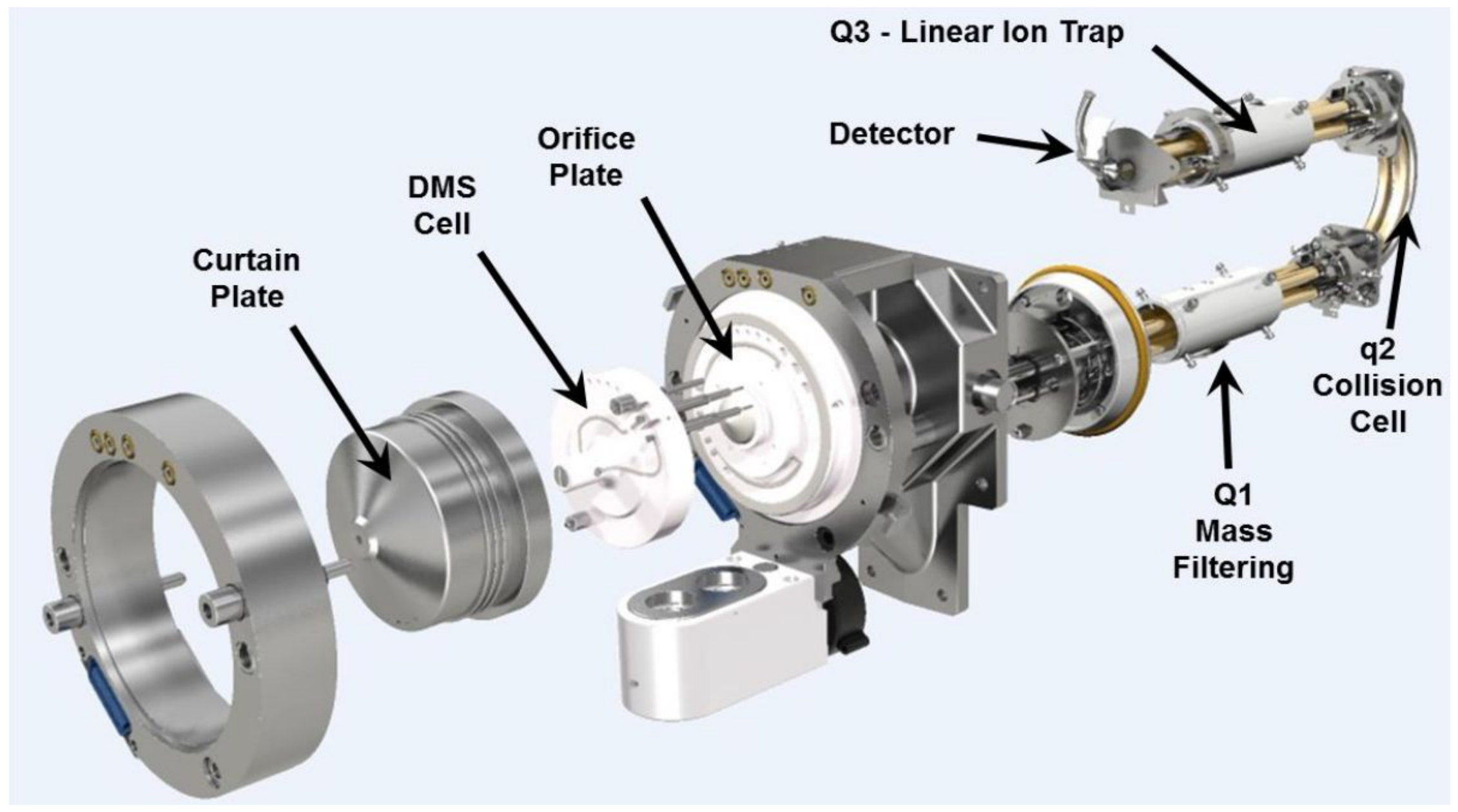

Figure S8. Schematic of the SelexION system coupled to the QTRAP 5500 (SCIEX) hybrid linear ion trap triple-quadrupole mass spectrometer. The QJet region shown in Figure S1 is not labelled but exists between the orifice plate and Q1. Experiments were conducted with the SelexION differential mobility spectrometry (DMS) cell attached and operating in transmission mode. 
Table S1. Activation energies $\left(E_{0}\right)$ and degrees of freedom for benzylypridinium, benzhydrylpyridinium, and benzylammonium thermometer ions. $E_{0}$ is calculated as a sum of the electronic and zero-point vibrational energy at the specified level of theory.

\begin{tabular}{|c|c|c|c|}
\hline Class & $\mathrm{R}, \mathrm{R}^{\prime}$ & $\mathrm{E}_{0} / \mathrm{kJ} \mathrm{mol}^{-1}$ & $N_{D o F}(3 N)$ \\
\hline \multirow{11}{*}{ Benzylpyridinium } & $\mathrm{OMe}^{\mathrm{a}}$ & 178.5 & 87 \\
\hline & $\mathrm{OEt}^{\mathrm{b}}$ & 172.1 & 96 \\
\hline & OiPr & 166.0 & 105 \\
\hline & $\mathrm{OtBu}$ & 160.4 & 114 \\
\hline & $\mathrm{Me}^{\mathrm{a}}$ & 219.0 & 84 \\
\hline & $\mathrm{tBu}^{\mathrm{c}}$ & 211.7 & 111 \\
\hline & $\mathrm{Cl}^{\mathrm{a}}$ & 228.7 & 75 \\
\hline & $\mathrm{F}^{\mathrm{a}}$ & 230.6 & 75 \\
\hline & $\mathrm{H}^{\mathrm{a}}$ & 241.2 & 75 \\
\hline & $\mathrm{CN}^{\mathrm{a}}$ & 264.4 & 78 \\
\hline & $\mathrm{NO}_{2}{ }^{\mathrm{c}}$ & 274.3 & 81 \\
\hline \multirow[t]{6}{*}{${\text { Benzhydrylpyridinium }{ }^{d}}^{\prime}$} & $\mathrm{H}, \mathrm{H}$ & 167.9 & 105 \\
\hline & $\mathrm{Me}, \mathrm{Me}^{\prime}$ & 146.7 & 123 \\
\hline & $\mathrm{H}, \mathrm{OMe}^{\prime}$ & 136.1 & 117 \\
\hline & $\mathrm{Me}, \mathrm{OMe}^{\prime}$ & 128.3 & 126 \\
\hline & OMe, OMe' & 113.9 & 129 \\
\hline & $\mathrm{NPh}_{2}, \mathrm{NPh}_{2}{ }^{\prime}$ & 67.5 & 237 \\
\hline \multirow{8}{*}{ Benzylammonium } & OMe & 105.8 & 66 \\
\hline & $\mathrm{Me}$ & 139.7 & 63 \\
\hline & $t \mathrm{Bu}$ & 134.5 & 90 \\
\hline & $\mathrm{Cl}$ & 152.0 & 54 \\
\hline & $\mathrm{F}$ & 152.8 & 54 \\
\hline & $\mathrm{H}$ & 163.4 & 54 \\
\hline & $\mathrm{CN}$ & 182.4 & 57 \\
\hline & $\mathrm{NO}_{2}$ & 196.7 & 60 \\
\hline
\end{tabular}

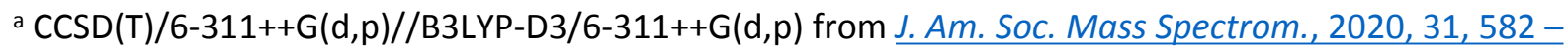
593.

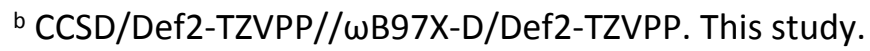

${ }^{c} \operatorname{CCSD}(T) / 6-311++G(d, p) / / B 3 L Y P / 6-311++G(2 d, p)$ from J. Chem. Phys., 2013, 138, 214301.

d DLPNO-CCSD(T)/various basis sets//PBEO-D3BJ/various basis sets; see Anal. Chem., 2019, 91, 11703 11711.

e CAM-B3LYP/6-311++G(d,p) from J. Am. Soc. Mass Spectrom., 2015, 26, $2081-2084$. 
Table S2. Instrumental settings for the QTRAP 5500 for the $\mathrm{MS}^{2}$ experiments as controlled by Analyst 1.7.

\begin{tabular}{|c|c|}
\hline Parameter & Setting \\
\hline \multicolumn{2}{|c|}{ Source } \\
\hline Curtain Gas (CUR) & 20.0 \\
\hline Ion spray voltage (IS) & 5500 \\
\hline Source Temperature (TEM) & 50 \\
\hline Nebulizing Gas Pressure (GS1) & 30.0 \\
\hline Auxiliary Gas Pressure (GS2) & 10.0 \\
\hline \multicolumn{2}{|c|}{ Compound } \\
\hline Declustering Potential (DP) & 100 \\
\hline Entrance Potential (EP) & 10 \\
\hline Collision Energy (CE) & Varies \\
\hline Collision Cell Exit Potential (CXP) & 15 \\
\hline \multicolumn{2}{|c|}{ DMS } \\
\hline DMS Temperature (DT) & Low \\
\hline Modifier (MD) & None \\
\hline Separation Voltage (SV) & 0.0 \\
\hline Compensation Voltage & 0.0 \\
\hline DMS Offset (DMO) & -3.0 \\
\hline DMS Resolution Enhancement (DR) & Off \\
\hline \multicolumn{2}{|c|}{ Resolution - Quad 1} \\
\hline Ion Energy 1 (IE1) & 1.1 \\
\hline Q1 Resolution & Unit \\
\hline \multicolumn{2}{|c|}{ Resolution - Quad 3} \\
\hline Ion Energy 3 (IE3) & 1.8 \\
\hline Q3 Resolution & Unit \\
\hline \multicolumn{2}{|c|}{ Detector } \\
\hline CEM (CEM) & 2100.0 \\
\hline
\end{tabular}




\section{Supplementary Section S1 - Synthesis of the benzylpyridinium derivatives}

\section{General Methods}

All reagents and solvents, including anhydrous solvents, were purchased from Sigma-Aldrich. Chromatography was performed using $60 \AA$ silica gel. High resolution mass spectra (HRMS) were obtained using an Thermo Scientific Q-Exactive Orbitrap mass spectrometer. Samples were ionized using electrospray ionization (ESI) in positive mode from $\mathrm{H}_{2} \mathrm{O} / \mathrm{MeOH}(1: 1)$ containing $0.1 \%$ formic acid.

\section{Synthesis of benzylpyridinium ions}

The synthesis of the O-alkylated benzylpyridinium species used in this study is outlined in Scheme S1.

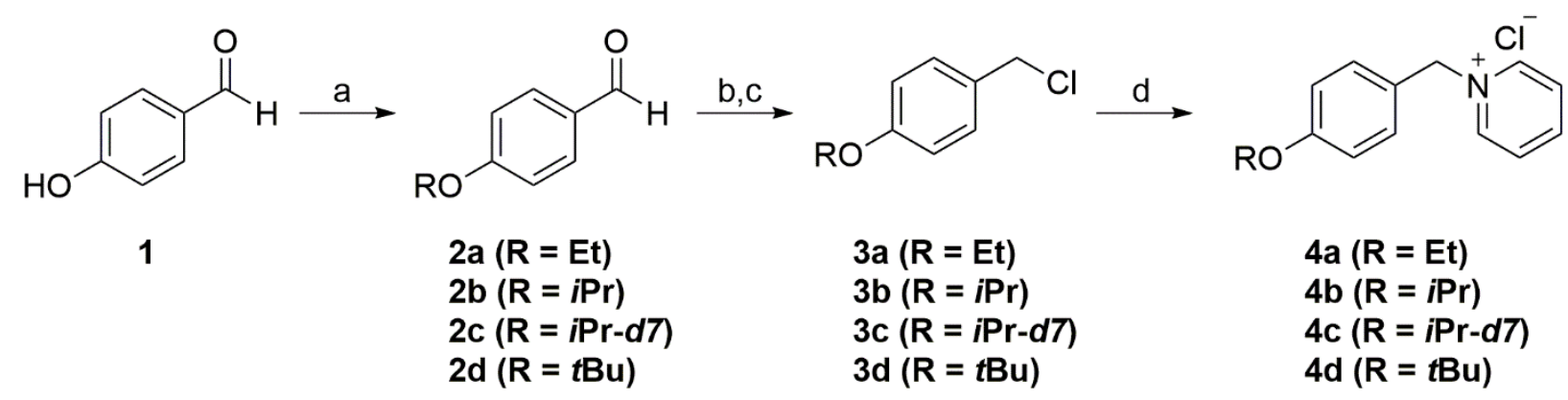

Scheme S1. Synthesis of the alkoxy benzylpyridinium ions used in this study. a. $\mathrm{K}_{2} \mathrm{CO}_{3}$, acetone, reflux, overnight. $\mathbf{R}=\mathbf{E t}$ : Et-I (95\%); $\mathbf{R}=\boldsymbol{i}-\operatorname{Pr}: i \operatorname{Pr}-\mathrm{Br}, \mathrm{Nal}(90 \%) ; \mathrm{R}=i-\operatorname{Pr}\left(d_{7}\right): i \operatorname{Pr}\left(d_{7}\right)-\mathrm{Br}, \mathrm{Nal}(89 \%) ; \mathbf{R}=\boldsymbol{t}-\mathrm{Bu}$ : $t \mathrm{Bu}-\mathrm{Br}, \mathrm{Nal}(66 \%)$. b. $\mathrm{NaBH}_{4}, \mathrm{EtOH}, \mathrm{rt}, 30 \mathrm{~min}$ c. $\mathrm{SOCl}_{2}$, ether, $0{ }^{\circ} \mathrm{C}-\mathrm{rt}, 3 \mathrm{~h}(90-95 \%)$. d. pyridine, $\mathrm{MeCN}$, rt, overnight ( $78-91 \%)$.

General procedure for the synthesis of O-alkylated 4-hydroxybenzaldehydes (2a-2d)

4-hydroxybenzaldhyde (1) (1.5g, $12.3 \mathrm{mmol}, 1$ eq.) was dissolved in acetone $(25 \mathrm{~mL})$ in a $100 \mathrm{~mL}$ roundbottomed flask equipped with a stir bar. $\mathrm{K}_{2} \mathrm{CO}_{3}(3.4 \mathrm{~g}, 24.6 \mathrm{mmol}, 2$ eq.) and the respective alkyl halide (Et-l, $i \mathrm{Pr}-\mathrm{Br}$, or $t \mathrm{Bu}-\mathrm{Br} ; 15.3 \mathrm{mmol}, 1.2 \mathrm{eq}$.) were added sequentially to the reaction flask. Reactions involving alkylbromides were treated with $\mathrm{Nal}(37 \mathrm{mg}, 0.246 \mathrm{mmol}, 0.02 \mathrm{eq}$.). The reaction was heated to reflux and stirred overnight.

After the reaction time, the reaction mixture was filtered and concentrated by rotary evaporation. The residue was partitioned over EtOAc $(40 \mathrm{~mL})$, then washed with $1 \mathrm{M} \mathrm{NaOH}(1 \times 40 \mathrm{~mL}), \mathrm{H}_{2} \mathrm{O}(1 \times 40 \mathrm{~mL})$, and brine $(1 \times 40 \mathrm{~mL})$. The organic layer was isolated, dried over $\mathrm{Na}_{2} \mathrm{SO}_{4}$, and concentrated to yield a pale yellow oil. Purification by flash chromatography (see specific compound entries for mobile phase) affords the desired O-alkylated benzaldehyde. 


\section{4-ethoxybenzaldehyde (2a)}

Compound 2a was prepared according to the General Procedure for the synthesis of O-alkylated benzaldehydes using ethyl iodide $(15.3 \mathrm{mmol}, 1.2$ eq.). Purification by flash chromatography (1:7 EtOAc:hexanes) as a clear oil (95\% yield). HRMS-ESI+ $(\mathrm{m} / \mathrm{z})$ : $[\mathrm{M}+\mathrm{H}]^{+}$calculated for $\mathrm{C}_{9} \mathrm{H}_{11} \mathrm{O}_{2}: 151.0759$; found 151.0755 .

\section{4-isopropoxybenzaldehyde (2b)}

Compound $\mathbf{2 b}$ was prepared according to the General Procedure for the synthesis of O-alkylated benzaldehydes using 2-bromopropane $(15.3 \mathrm{mmol}, 1.2$ eq.). Purification by flash chromatography (1:8 EtOAc:hexanes) as a clear oil (90\% yield). HRMS-ESI+ $(\mathrm{m} / \mathrm{z})$ : $[\mathrm{M}+\mathrm{H}]^{+}$calculated for $\mathrm{C}_{10} \mathrm{H}_{13} \mathrm{O}_{2}: 165.0916$; found 165.0910 .

\section{4-isopropoxy $\left(d_{7}\right)$ benzaldehyde $(2 \mathrm{c})$}

Compound 2c was prepared according to the General Procedure for the synthesis of O-alkylated benzaldehydes using 2-bromopropane $\left(d_{7}\right)(15.3 \mathrm{mmol}, 1.2$ eq.). Purification by flash chromatography ( $1: 8$ EtOAc:hexanes) as a clear oil (89 \% yield). HRMS-ESI+ $(\mathrm{m} / \mathrm{z}):[\mathrm{M}+\mathrm{H}]^{+}$calculated for $\mathrm{C}_{10} \mathrm{H}_{6} \mathrm{D}_{7} \mathrm{O}_{2}: 172.1355$; found 172.1362 .

\section{4-(tert-butoxy)benzaldehyde (2d)}

Compound $\mathbf{2 b}$ was prepared according to the General Procedure for the synthesis of O-alkylated benzaldehydes using 2-bromo-2-methylpropane (15.3 mmol, 1.2 eq.). Purification by flash chromatography (1:9 EtOAc:hexanes) as a clear oil (66\% yield). HRMS-ESI+ $(m / z):[\mathrm{M}+\mathrm{H}]^{+}$calculated for $\mathrm{C}_{11} \mathrm{H}_{15} \mathrm{O}_{2}$ : 179.1072; found 179.1068 .

\section{General procedure for the synthesis of O-alkylated benzylchlorides (3a-3d)}

$2(5.87 \mathrm{mmol}, 1$ eq.) was solubilized in $\mathrm{EtOH}(10 \mathrm{~mL})$ in a $50 \mathrm{~mL}$ round-bottom flask equipped with a stir bar. Sodium borohydride ( $302 \mathrm{mg}, 8 \mathrm{mmol}, 1.36 \mathrm{eq}$.) was added portion-wise to the reaction mixture with vigorous stirring over 2 minutes at room temperature. The reaction was monitored by TLC (1:2 EtOAc/Hexanes) until completion (30 min). Upon completion, the reaction was quenched with $6 \mathrm{M} \mathrm{HCl}$ (added dropwise) until $\mathrm{H}_{2}$ evolution ceases. The reaction mixture was subsequently concentrated by rotary evaporation, partitioned over EtOAc $(30 \mathrm{~mL})$, then washed with $1 \mathrm{M} \mathrm{HCl}(1 \times 30 \mathrm{~mL}), \mathrm{H}_{2} \mathrm{O}$ $(1 \times 30 \mathrm{~mL})$, and brine $(1 \times 30 \mathrm{~mL})$. The organic layer was isolated, dried over $\mathrm{Na}_{2} \mathrm{SO}_{4}$, and concentrated to yield a clear oil. All material was carried forward to the subsequent step without further purification. Crude benzylalcohol was added to an oven-dried $50 \mathrm{~mL}$ round-bottomed flask equipped with a stir bar and purged with $\mathrm{N}_{2}$. The benzylalcohol was solubilized in anhydrous diethyl ether $(7.5 \mathrm{~mL})$ and cooled in an ice bath prior to the dropwise addition of $\mathrm{SOCl}_{2}$ (2 eq.). After the addition, the ice-bath was removed and the reaction was stirred at room temperature for 3 hours.

Upon completion, $5 \mathrm{~mL}$ of $\mathrm{H}_{2} \mathrm{O}$ was added to the reaction flask, which was stirred in open air for 5 minutes. The reaction mixture was subsequently partitioned over EtOAc $(30 \mathrm{~mL})$, then washed $\mathrm{H}_{2} \mathrm{O}(2 \times 30 \mathrm{~mL})$ and brine $(1 \times 30 \mathrm{~mL})$. The organic layer was isolated, dried over $\mathrm{Na}_{2} \mathrm{SO}_{4}$, and concentrated to yield the desired O-alkylated benzylchloride. 


\section{1-(chloromethyl)-4-ethoxybenzene (3a)}

Compound 3a was prepared according to the General Procedure for the synthesis of O-alkylated benzyl chlorides without further purification to yield a clear oil (95\% yield) that is pure by TLC (1:3 EtOAc/haxanes). HRMS-ESI+ $(m / z):[\mathrm{M}+\mathrm{H}]^{+}$calculated for $\mathrm{C}_{9} \mathrm{H}_{12} \mathrm{ClO}: 171.0577$; found .

\section{1-(chloromethyl)-4-isopropoxybenzene (3b)}

Compound $\mathbf{3 b}$ was prepared according to the General Procedure for the synthesis of O-alkylated benzyl chlorides without further purification to yield a clear oil $(92 \%$ yield) that is pure by TLC (1:3 EtOAc/haxanes). HRMS-ESI+ (m/z): [M + H] $]^{+}$calculated for $\mathrm{C}_{10} \mathrm{H}_{14} \mathrm{ClO}$ : 185.0733; found 185.0737.

\section{1-(chloromethyl)-4-((propan-2-yl-d7)oxy)benzene (3c)}

Compound 3c was prepared according to the General Procedure for the synthesis of O-alkylated benzyl chlorides without further purification to yield a clear oil ( $94 \%$ yield) that is pure by TLC (1:3 EtOAc/haxanes). HRMS-ESI+ $(\mathrm{m} / \mathrm{z})$ : $[\mathrm{M}+\mathrm{H}]^{+}$calculated for $\mathrm{C}_{10} \mathrm{H}_{7} \mathrm{D}_{7} \mathrm{ClO}$ : 192.1172; found 192.1176 .

1-(tert-butoxy)-4-(chloromethyl)benzene (3d)

Compound 3d was prepared according to the General Procedure for the synthesis of O-alkylated benzyl chlorides without further purification to yield a clear oil $(90 \%$ yield) that is pure by TLC (1:3 EtOAc/haxanes). HRMS-ESI+ (m/z): [M + H] ${ }^{+}$calculated for $\mathrm{C}_{11} \mathrm{H}_{16} \mathrm{ClO}$ : 199.0890; found 199.0898.

\section{General procedure for the synthesis of O-alkylated benzylpyridinium chlorides (4a-4d)}

3 (3.23 mmol, 1 eq.) was dissolved in anhydrous acetonitrile $(5 \mathrm{~mL})$ in an oven-dried $25 \mathrm{~mL}$ roundbottomed flask equipped with a stir bar and purged with $\mathrm{N}_{2}$. Anhydrous pyridine ( $3 \mathrm{~mL}, 16.15 \mathrm{mmol}, 5$ eq.) was added and the reaction was stirred overnight at room temperature under a positive pressure of $\mathrm{N}_{2}$.

After the reaction time, the reaction mixture was co-evaporated with hexanes to yield a milky-white liquid. Trituration with anhydrous diethyl ether $(5 \times 10 \mathrm{~mL})$ afforded the desired benzylpyridinium chloride.

\section{1-(4-ethoxybenzyl)pyridin-1-ium chloride (4a)}

Compound 4a was prepared according to the General Procedure for the synthesis of O-alkylated benzylpyridnium chlorides to yield a white powder (84\% yield). HRMS-ESI+ $(m / z):[\mathrm{M}+\mathrm{H}]^{+}$calculated for $\mathrm{C}_{14} \mathrm{H}_{16} \mathrm{NO}$ : 214.1232; found 214.1228.

\section{1-(4-isopropoxybenzyl)pyridin-1-ium chloride (4b)}

Compound $\mathbf{4 c}$ was prepared according to the General Procedure for the synthesis of O-alkylated benzylpyridnium chlorides to yield a white powder (78\% yield). HRMS-ESI+ $(m / z):[M+H]^{+}$calculated for $\mathrm{C}_{15} \mathrm{H}_{18} \mathrm{NO}$ : 228.1388; found 228.1394.

\section{1-(4-((propan-2-yl-d7)oxy)benzyl)pyridin-1-ium chloride (4c)}

Compound $\mathbf{4 c}$ was prepared according to the General Procedure for the synthesis of O-alkylated benzylpyridnium chlorides to yield a white powder (91\% yield). HRMS-ESI+ $(\mathrm{m} / \mathrm{z}):[\mathrm{M}+\mathrm{H}]^{+}$calculated for $\mathrm{C}_{15} \mathrm{H}_{11} \mathrm{D}_{7} \mathrm{NO}$ : 235.1828; found 235.1832. 
1-(4-isopropoxybenzyl)pyridin-1-ium chloride (4d)

Compound $\mathbf{4 d}$ was prepared according to the General Procedure for the synthesis of O-alkylated benzylpyridnium chlorides to yield a white powder (81\% yield). HRMS-ESI+ $(\mathrm{m} / \mathrm{z})$ : $[\mathrm{M}+\mathrm{H}]^{+}$calculated for $\mathrm{C}_{15} \mathrm{H}_{18} \mathrm{NO}$ : 242.1545; found 242.1553. 